\section{¿Es la medicina hospitalaria una alternativa para nuestros internistas?}

\section{Hospital Medicine: An alternative for our Internists?}

Sr. Editor: He leído con mucho interés el reciente artículo de Berkovits et al ${ }^{1}$. Agradezco y felicito la iniciativa y tenacidad con que este grupo de jóvenes internistas del Hospital Clínico de la Pontificia Universidad Católica de Chile ha promovido el modelo hospitalista de atención, abriendo una ventana para su aplicación en nuestro país.

El modelo de Medicina Hospitalista ${ }^{2}$ se difundió rápidamente en la última década en los hospitales generales de Estados Unidos de Norteamérica (EEUU) y Canadá. Su éxito se basa en dos grandes ventajas respecto al modelo tradicional: primera, promueve la integración en el tratamiento de pacientes en unidades médico quirúrgicas generales, desalentando el fraccionamiento del cuidado médico en subespecialidades, práctica que reconocidamente aumenta los costos y prolonga la estadía hospitalaria; segunda, en el caso de pacientes quirúrgicos, los cirujanos transfieren la responsabilidad del manejo pre y posquirúrgico, y dedican su tiempo preferentemente al pabellón de operaciones. Los esfuerzos de diversos grupos de hospitalistas se han centrado en demostrar que tal modelo de atención reduce de manera significativa los costos de hospitalización ${ }^{3,4}$.

No existe unanimidad respecto a las ventajas del modelo hospitalista, sobre todo por las opiniones de médicos generales e internistas dedicados a la manera tradicional en la cual, como tratantes, ven pacientes tanto en la consulta y durante su hospitalización, y que se oponen al nuevo modelo porque puede despersonalizar o desperfilar el rol del "médico de cabecera". Sin embargo, el modelo hospitalista creció cuando tales tratantes se dieron cuenta de que contar con un médico hospitalista a cargo de su paciente es más beneficioso en términos de evitar el desplazamiento desde la consulta a la Clínica u Hospital, optimizando el uso del escaso tiempo ${ }^{3}$. Como respuesta natural al mayor tiempo en el Servicio clínico, los hospitalistas se involucraron en el quehacer hospitalario, con la calidad de la atención y los procesos que requiere la atención del paciente desde su ingreso al alta, la comunicación con la familia y ciertos aspectos administrativos y de gestión clínica. Estudios del grado de satisfacción del personal de enfermería respecto al desempeño médico son claros en preferir el modelo hospitalista por contar con un especialista formado en el ámbito hospitalario, cercano y disponible 24 horas al día, capaz de resolver los problemas clínicos cotidianos con una latencia inferior al modelo tradicional ${ }^{5}$.

Por otro lado, parece ir en aumento el interés de los internistas por ejercer una especialidad en que dispongan de tiempo libre más programable, evitando los turnos de llamada, los turnos de noche y durante los fines de semana.

Desde un punto de vista laboral, los hospitalistas tienden a organizarse en equipos de trabajo que ofrecen sus servicios a diversas instituciones de salud, práctica homologable al outsourcing, negociando sus condiciones salariales colectivamente.

Así, el número de internistas que se declaran hospitalistas ha crecido exponencialmente en Norteamérica, asumiendo, además, labores docentes y formativas para nuevos hospitalistas. Se fundó la Society for Hospital Medicine al alero del American College of Physicians y surgieron varias revistas médicas del tema, con comités editoriales serios y revisión por pares.

La Medicina Hospitalista no se reconoce todavía como una subespecialidad, en Estados Unidos de Norteamérica, aunque existen programas de formación en ella, y se cuenta con un core curriculum respecto a conocimientos, destrezas y habilidades que deben cumplir los internistas que acceden a dichos programas.

\section{¿Por qué en Chile no ha crecido esta nueva manera de ver la Medicina Interna?}

Probablemente existe en nuestro país el mismo temor de desperfilar el rol del médico tratante, quien ve en la hospitalización de sus propios pacientes una manera de entender integralmente la Medicina Interna, cultivar la relación médico paciente y mantenerse actualizado en aspectos clínicos del ámbito hospitalario. El concepto de continuidad en la relación del paciente con su médico tratante es muy arraigado, especialmente en la medicina privada. Es frecuente aún escuchar el término " yo soy paciente del Dr. X".

Del punto de vista económico, para un internista el hecho de depender de un único sueldo como fuente de ingresos implica un riesgo que pocos están dispuestos a correr, sobre todo en un mercado de la salud con una complejidad creciente 
y una alta competencia. Sin duda, existe el temor a una progresiva disminución de los sueldos reales como un mecanismo de control de los crecientes costos en Salud. El hecho de que existan escasos instrumentos de defensa ante los empleadores de este mercado, probablemente deteriora las posibilidades de un internista general para arriesgar su condición actual.

El problema del burnout asociado a una sobrecarga asistencial está también presente ${ }^{6}$, tanto en EEUU como en nuestra realidad, y en nuestra salud privada y pública el número creciente de ingresos a unidades de Medicina crece según el progresivo envejecimiento poblacional y el aumento de patologías crónicas no transmisibles. Los pacientes se hacen cada día más complejos y, ante la falta de límites precisos respecto al ámbito de acción de los hospitalistas, puede llegar a ser un problema difícil de resolver, que atentaría contra el interés de nuevos internistas por seguir este camino.

Las múltiples ventajas que ofrece el modelo hospitalista de atención, en términos de dedicación exclusiva a pacientes hospitalizados con énfasis en aspectos de calidad, la coordinación entre diversas especialidades médico quirúrgicas, y los indudables beneficios académicos y formativos que muy bien han explicitado el Dr. Berkovits y colaboradores en su artículo, me hacen pensar que iniciativas como las de su hospital deberían naturalmente permear en nuestro medio hospitalario, no sólo por un convencimiento basado en evidencias sino, además, en la reducción en los costos en Salud que para los sistemas público y privado significaría su implementación.

$$
\begin{array}{r}
\text { Iván Solís } \\
\text { 'Departamento de Medicina } \\
\text { (Campus Centro), Facultad de Medicina de la } \\
\text { Universidad de Chile. } \\
\text { Hospital San Borja Arriarán. } \\
{ }^{2} \text { Unidad de Tratamiento Intermedio, Clínica } \\
\text { Dávila, Santiago de Chile. }
\end{array}
$$

\section{Referencias}

1. Berkovits A, Aizman A, Eymin G, Rojas L. Medicina hospitalaria. Rev Méd Chile 2009; 137: 1385-7.

2. Wachter RM, Goldman L. The emerging role of "hospitalists" in the American health care system. N Engl J Med 1996; 335: 514-7.

3. Everett G, Uddin N, Rudloff B. RN Comparison of Hospital Costs and Length of Stay for Community Internists, Hospitalists, and Academicians. J General Intern Med 2007; 22: 662-7.

4. Phy MP, Vanness DJ, Melton J, Long KH, Schleck CD, Larson DR, et al. Effects of a hospitalist model on elderly patients with hip fracture. Arch Intern Med 2005; 165 : 796-801.

5. Huddleston JM, Long KH, Naessens JM, Vanness D, Larson D, Trousdale R, et al. Medical and Surgical Comanagement after Elective Hip and Knee Arthroplasty. Ann Intern Med 2004; 141: 28-38.

6. Hoff TH, Whitcomb WF, Williams K, Nelson JR, Cheesman RA. Characteristics and work experiences of hospitalists in the United States. Arch Intern Med 2001; 161: 851-8.

Correspondencia a:

Dr. Iván Solís Opazo

Departamento de Medicina Campus Centro

Universidad de Chile. Hospital Clínico San Borja-Arriarán, Santa Rosa 1234. Fono 56-2-9770019.

E-mail ivansolis@med.uchile.cl 